\title{
Renal Infarction in a Patient with Pulmonary Vein Thrombosis after Left Upper Lobectomy
}

\author{
Shun Manabe Yasuko Oshima $^{\mathrm{a}}$ Marie Nakano $^{\mathrm{a}}$ Teruhiro Fujii $^{\mathrm{a}}$ \\ Takamitsu Maehara $^{b}$ Kosaku Nitta $^{c}$ Michiyasu Hatano ${ }^{a}$ \\ Departments of a Nephrology and ${ }^{b}$ Thoracic Surgery, Yokohama Rosai Hospital, \\ Yokohama, and 'Department of Medicine, Kidney Center, Tokyo Women's Medical \\ University, Tokyo, Japan
}

\section{Key Words}

Renal infarction · Pulmonary vein thrombosis · Lung resection $\cdot$ Peripheral infarction · Lung cancer

\begin{abstract}
A 43-year-old male experienced renal infarction (RI) following left upper lobectomy for lung cancer. The patient complained of acute-onset severe left flank pain on the 14th postoperative day. A contrast-enhanced computed tomography (CT) of the abdomen revealed RI by a large wedge-shaped defect in the left kidney. A chest CT scan located the thrombus in the stump (a blind-ended vessel) of the left superior pulmonary vein. Therefore, thromboembolic RI caused by pulmonary vein thrombosis was suspected. Anticoagulation therapy was initiated with heparin and warfarin to treat RI and to prevent further embolic episodes. Two months later, pulmonary vein thrombosis had resolved without the appearance of additional peripheral infarction. This case emphasizes the need to consider thrombus in the stump of the pulmonary vein as a cause of RI.

(c) 2014 S. Karger AG, Basel
\end{abstract}

\section{Introduction}

Renal infarction (RI) is caused by sudden disruption of blood flow in the renal arteries, and rapid diagnosis and treatment is critical to prevent permanent loss of renal function. However, clinical diagnosis of RI is often difficult and frequently missed or delayed because of its low prevalence and nonspecific symptoms such as abdominal or flank pain, which are frequently found in other more common conditions such as nephrolithiasis and pyelonephri-

Kosaku Nitta, MD, PhD

Department of Medicine

Kidney Center, Tokyo Women's Medical University

8-1 Kawada-cho, Shinjuku-ku, Tokyo 162-8666 (Japan)

E-Mail knitta@kc.twmu.ac.jp 
tis. To make an accurate diagnosis of RI, it is essential to raise a suspicion for this condition from a thorough patient medical history and to proceed with an optimal diagnostic workup [1].

The 2 major causes of RI are systemic arterial thromboembolism, which usually originates from a thrombus in the heart or aorta, and in situ thrombus formation following injury of the renal artery, such as renal artery dissection [1]. After ruling out in situ thrombus formation, disclosure of the pathogenesis of thrombosis and detection of thrombus is necessary to provide appropriate treatment. Previous reports suggest that the majority of RIs occurs in patient with atrial fibrillation [2]. However, in recent reports, RIs caused by atrial fibrillation decreased to $18-37 \%$, while cases without known detectable cause increased to $13-30 \%$ [2-4]. Therefore, it is important to look for previously unrecognized etiologies of RI to make accurate causal diagnoses.

In this report, we present a case of RI with thrombus formation in the stump (a blindended vessel) of the left superior pulmonary vein shortly after lung resection. We also reviewed the relevant literature, which may be indicative of a causal relationship between RI and pulmonary vein thrombosis.

\section{Case Report}

A 43-year-old male ex-smoker, without concomitant conditions, was diagnosed with adenocarcinoma and underwent a formal left upper lobectomy in combination with mediastinal lymph node sampling (fig. 1a). The procedure was uncomplicated, but the patient received pleural adhesion therapy for the treatment of prolonged postoperative air leaks. Following pleural adhesion, the postoperative period was uneventful. The patient was discharged on the 13th postoperative day.

The day after discharge, the patient presented to our emergency department with complaints of a sudden onset of severe flank pain located at the lower side of the left hemithorax. Body temperature was $39.4^{\circ} \mathrm{C}$. Laboratory data showed an elevation of white blood cells $\left(10,000\right.$ cells $\left./ \mathrm{m}^{2}\right)$, serum lactate dehydrogenase $(778 \mathrm{U} / \mathrm{l})$, creatinine $(0.82 \mathrm{mg} / \mathrm{dl} ; 0.63$ $\mathrm{mg} / \mathrm{dl}$ before discharge), C-reactive protein $(7.75 \mathrm{mg} / \mathrm{dl})$, and plasma D-dimer $(9.18 \mu \mathrm{g} / \mathrm{ml})$. The urine was negative for occult blood. Contrast-enhanced computed tomography (CT) of the abdomen revealed a large wedge-shaped infarction of the left kidney (fig. 1b). The wellknown causes of RI such as left atrial thrombus, (paroxysmal) atrial fibrillation, aortic plaque, renal artery stenosis or dissection, and deep vein thrombosis with right-to-left shunt were not identified by evaluations including transthoracic echocardiogram, ambulatory electrocardiography, renal artery CT angiography, and lower limbs venous ultrasonography. In addition, his laboratory evaluation for inherited and acquired hypercoagulable states, such as protein $\mathrm{C}$ or protein $\mathrm{S}$ deficiencies and antiphospholipid antibody syndrome, were negative.

These results were consistent with idiopathic RI. However, because the onset was shortly after lung resection, an explorative contrast-enhanced CT scan of the chest was performed. The CT scan revealed thrombus in the stump of the left superior pulmonary vein (fig. 1c, d). Anticoagulation therapy was initiated with continuous intravenous heparin injection (10,000 units per day) and followed by warfarin therapy to maintain control of PTINR between 1.5 and 2.0. Laboratory findings worsened over the following 3 days (lactate dehydrogenase $1,530 \mathrm{U} / \mathrm{l}$; creatinine $0.95 \mathrm{mg} / \mathrm{dl}$ ) but then gradually returned to normal. Under anticoagulation therapy, renal functions partially recovered (creatinine $0.75 \mathrm{mg} / \mathrm{dl}$ ) within 1 month, and the pulmonary vein thrombosis resolved within 2 months with no 
Manabe et al.: Renal Infarction in a Patient with Pulmonary Vein Thrombosis after Left Upper Lobectomy

additional peripheral infarction (fig. 1e). After cessation of anticoagulation therapy, there was no recurrence of pulmonary vein thrombosis throughout the follow-up period.

\section{Discussion}

We described an unusual case of RI that occurred 14 days after lung resection. After an extended evaluation, a thrombus was detected in the stump of the left superior pulmonary vein. Because none of the known causes of RI were detectable in our patient, thromboembolic RI caused by a pulmonary vein thrombosis was strongly suspected.

According to the literature, risk factors of thromboembolic RI, other than atrial fibrillation, include valvular or ischemic heart disease, endocarditis, hypercoagulation disorders, and hematological diseases [1]. Because thromboembolic RIs are arterial vascular events, detection of thrombus begins with transthoracic echocardiogram to disclose intra-atrial thrombus. Subsequently, the presence of a thrombus at the atherosclerotic and/or aneurysmatic aorta is examined in usual causal diagnosis workup. However, origins of thromboembolism are not limited to systemic arterial circulation. For example, in cases with atrial septal defects or patent foramen ovale, venous thrombus may transverse from the venous system to the systemic arterial circulation to cause thromboembolic RI [5]. Another exception is the pulmonary vein, which carries arterial blood to the left atrium. After major lung resection, a stump of the pulmonary vein is created, and a thrombus generated in the stump may easily enter the systemic circulation and cause thromboembolic RI.

To the best of our knowledge, only 5 cases of RI following lung resections have been reported [6-10] (table 1) and none of these cases had detectable well-known causes of RI. One patient, who suffered from RI 13 months after surgery, had a graphically confirmed pulmonary vein thrombosis similar to our case [7]. The remaining 4 patients who had RI in the early postoperative period [6, 8-10] were diagnosed as idiopathic RI, which may be correlated with the postoperative $[6,10]$ and/or paraneoplastic [8-10] hypercoagulable state. However, the co-existence of thrombus in the pulmonary vein was not examined in 3 cases $[6,8,10]$ and not mentioned in 1 case [9] because pulmonary vein thrombosis have not been previously described as risk factors for RI.

There were 5 other reported cases with peripheral embolic events other than RI after lung resection with graphically detectable pulmonary vein thrombosis [11-15] (table 2). Assessing similarities between these cases, RI occurred after left upper lobectomy in all cases [6-10], and all thrombi were detected in the left superior pulmonary vein [7, 11-15]. Based on this similarity, we speculate that pulmonary vein thrombosis after left upper lobectomy is an unrecognized risk factor for thromboembolic RI.

Thrombus in the stump of the pulmonary vein has rarely been reported and has been thought to be a very rare phenomenon until the past few years [16]. However, Nagaoka et al. [7] reported that 2 of 31 patients developed a thrombus in the stump of the pulmonary vein after lung resection. In addition, Ohtaka et al. [16] reported that 7 of 193 patients had thrombus after lung resection, all of which were detected in cases with left upper lobectomy. From these reports, pulmonary vein thrombosis seems to be a more frequent complication following lung resection than recognized previously. In contrast, there are a few reports suggesting a relationship between pulmonary vein thrombosis and peripheral infarction. This might be because the pulmonary vein stump is usually not examined as a potential origin of thromboembolism, and therefore, this relationship might be underdiagnosed.

In our patient and 1 previously reported RI case with successful detection of pulmonary vein thrombosis, anticoagulation therapy was indicated to treat RI and to prevent further 
Manabe et al.: Renal Infarction in a Patient with Pulmonary Vein Thrombosis after Left Upper Lobectomy

embolic episodes [5]. In both cases, anticoagulation therapy successfully dissolved the pulmonary vein thrombus and prevented new embolic episodes. However, the optimal duration of anticoagulation therapy and the risk of the reformation of a thrombus after cessation of anticoagulation therapy are not well defined. Because there are so few reported cases, further investigation of the optimal treatment of these conditions is necessary.

In summary, we encountered an unusual case of RI, which was likely caused by pulmonary vein thrombosis following left upper lobectomy. In addition, the occurrence of thrombus formation in the stump of the left superior pulmonary vein is more frequent than presumed previously. Therefore, a history of left upper lobectomy should be considered as a potential risk factor for RI, and pulmonary vein thrombosis needs to be regarded as an origin of thromboembolism to make an accurate causal diagnosis of RI.

\section{Disclosure Statement}

There are no conflicts of interest.

\section{References}

1 Khawer Saeed: Renal infarction. Int J Nephrol Renovasc Dis 2012;5:199-123.

-2 Bolderman R, Oyen R, Verrijcken A, Knockaert D, Vanderschueren S: Idiopathic renal infarction. Am J Med 2006;119:356.e9-e12.

3 Antopolsky M, Simanovsky N, Stalnkowicz R, Salameh S, Hiller N: Renal infarction in the ED: 10-year experience and review of the literature. Am J Emerg Med 2012;30:1055-1060.

4 Bourgault M, Grimbert P, Verret C, Pourrat J, Herody M, Halimi JM, Karras A, Amoura Z, Jourde-Chiche N, Izzedine H, Francois H, Boffa JJ, Hummel A, Bernadet-Monrozies P, Fouque D, Canoui-Poitrine F, Lang P, Daugas E, Audard V: Acute renal infarction: a case series. Clin J Am Soc Nephrol 2013;8:392-398.

5 Carey HB, Boltax R, Dickey KW, Finkelstein FO: Bilateral renal infarction secondary to paradoxical embolism. Am J Kidney Dis 1999;34:752-755.

6 Oura H, Hirose M, Aikawa H, Ishiki M: Abdominal organ infraction encountered immediately after surgery of primary lung cancer. Kyobu Geka 2005;58:137-142. (Japanese)

7 Nagaoka E, Yano M, Sugano T, Miyamoto T: Thrombus in the left superior pulmonary vein after left upper pulmonary lobectomy. J Thorac Cardiovasc Surg 2008;135:709-710.

8 Sawada T, Watanabe Y, Ohura H: Abdominal organ infarction encountered after surgery for primary lung cancer. Nippon Kyobu Geka Gakkai Zasshi 2009;23:161-164. (Japanese)

$\$ 9$ Asteriou C, Barbetakis N, Efstathiou A, Kleontas A, Tsilikas C: Renal artery thrombosis following lobectomy for lung cancer. Case Rep Oncol 2010;3:208-211.

10 Tamaki M, Miura K, Norimura K, Kenzaki K, Yosizawa K: Renal infarction and acute obstruction of the lower extremity encountered after surgery for primary lung cancer. Kyobu Geka 2013;66:138-141. (Japanese)

11 Seki M, Endo M, Kidani M, Kobayashi H, Sato H, Noto T: A rare case of left atrial thrombus after left upper pulmonary lobectomy. Nihon Kyobu Geka Gakkai Zasshi 1989;37:1371-1375. (Japanese)

$\checkmark 12$ Schwalm S, Ward RP, Spencer KT: Transient ischemic attack in patient with pulmonary vein thrombosis after left upper lobectomy for squamous cell lung cancer. J Am Soc Echocardiogr 2004;17:487-488.

13 Ohtaka K, Hida Y, Kaga K, limura Y, Shiina N, Muto J, Hirano S: Pulmonary vein thrombosis after videoassisted thoracoscopic left upper lobectomy. J Thorac Cardiovasc Surg 2012;143:e3-e5.

14 Gual-Capllonch F, Teis A, Palomeras E: Pulmonary vein spontaneous echocontrast and stroke after pulmonary lobectomy. J Clin Ultrasound 2013;41:321-322.

15 Asai K, Mochizuki T, Iizuka S, Momiki S, Suzuki K: Pulmonary vein stump thrombus: an early complication following upper division segmentectomy of the left lung. Gen Thorac Cardiovasc Surg 2014;62:244-247.

16 Ohtaka K, Hida Y, Kaga K, Kato T, Muto J, Nakada-Kubota R, Sasaki T, Matsui Y: Thrombosis in the pulmonary vein stump after left upper lobectomy as a possible cause of cerebral infarction. Ann Thorac Surg 2013;95:1924-1928. 
Manabe et al.: Renal Infarction in a Patient with Pulmonary Vein Thrombosis after Left Upper Lobectomy

Table 1. Reported cases of renal infarction after pulmonary resection

\begin{tabular}{|c|c|c|c|c|c|c|c|}
\hline Year & Age/sex & Diagnosis & $\begin{array}{l}\text { Concomitant } \\
\text { conditions }\end{array}$ & PVT & Procedure & Intervala $^{a}$ & Ref. \\
\hline 2005 & $70 / \mathrm{m}$ & RI & DM, HT & - & LUL & 4 days & 6 \\
\hline 2008 & $76 / \mathrm{m}$ & RI & NR & + & LUL & 13 months & 7 \\
\hline 2009 & $52 / \mathrm{f}$ & RI & asthma & - & LUL & 0 days & 8 \\
\hline 2010 & $53 / f$ & RI & none & - & LUL & 3 days & 9 \\
\hline 2013 & $68 / \mathrm{m}$ & $\begin{array}{l}\text { RI, acute arterial } \\
\text { obstruction }\end{array}$ & $\mathrm{HT}, \mathrm{CI}$ & - & LUL & 4 days & 10 \\
\hline 2014 & $43 / \mathrm{m}$ & RI & none & + & LUL & 14 days & present case \\
\hline
\end{tabular}

PVT = Pulmonary vein thrombosis; RI = renal infarction; DM = diabetes mellitus; HT = hypertension; LUL = left upper lobectomy; NR = not reported; $\mathrm{CI}=$ cerebral infarction.

Table 2. Reported cases of pulmonary vein stump thrombus and peripheral embolic episode

\begin{tabular}{llllllll}
\hline Year & Age/sex & Diagnosis & $\begin{array}{l}\text { Concomitant } \\
\text { conditions }\end{array}$ & $\begin{array}{l}\text { Location of } \\
\text { thrombus }\end{array}$ & Procedure & Intervala & Ref. \\
\hline 1989 & $75 / \mathrm{m}$ & $\begin{array}{l}\text { acute arterial } \\
\text { obstruction }\end{array}$ & SSS & LSPV & LUL & 6 months & 11 \\
2004 & $73 / \mathrm{m}$ & TIA & DM, HT, CAD & LSPV & LUL & 20 days & 12 \\
2009 & $76 / \mathrm{m}$ & RI & NR & LSPV & LUL & 13 months & 7 \\
2012 & $66 / \mathrm{m}$ & CI & cancerb & LSPV & LUL & 18 months & 13 \\
2013 & $70 / \mathrm{m}$ & CI & HL & LSPV & LUL & 7 years & 14 \\
2014 & $76 / \mathrm{f}$ & TIA & cancerc & LSPV & LUDS & 2 days & 15 \\
2014 & $43 / \mathrm{m}$ & RI & none & LSPV & LUL & 14 days & present case \\
\hline
\end{tabular}

SSS = Sick sinus syndrome; LSPV = left superior pulmonary vein; TIA = transient ischemic attack; CAD = coronary artery

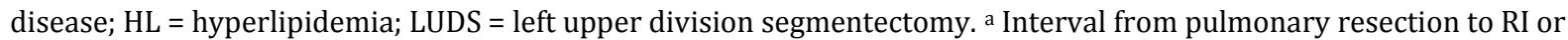
peripheral embolic episode. b Maxillary, oropharyngeal, and tongue cancer. c Metastatic colon cancer. 
Manabe et al.: Renal Infarction in a Patient with Pulmonary Vein Thrombosis after Left Upper Lobectomy

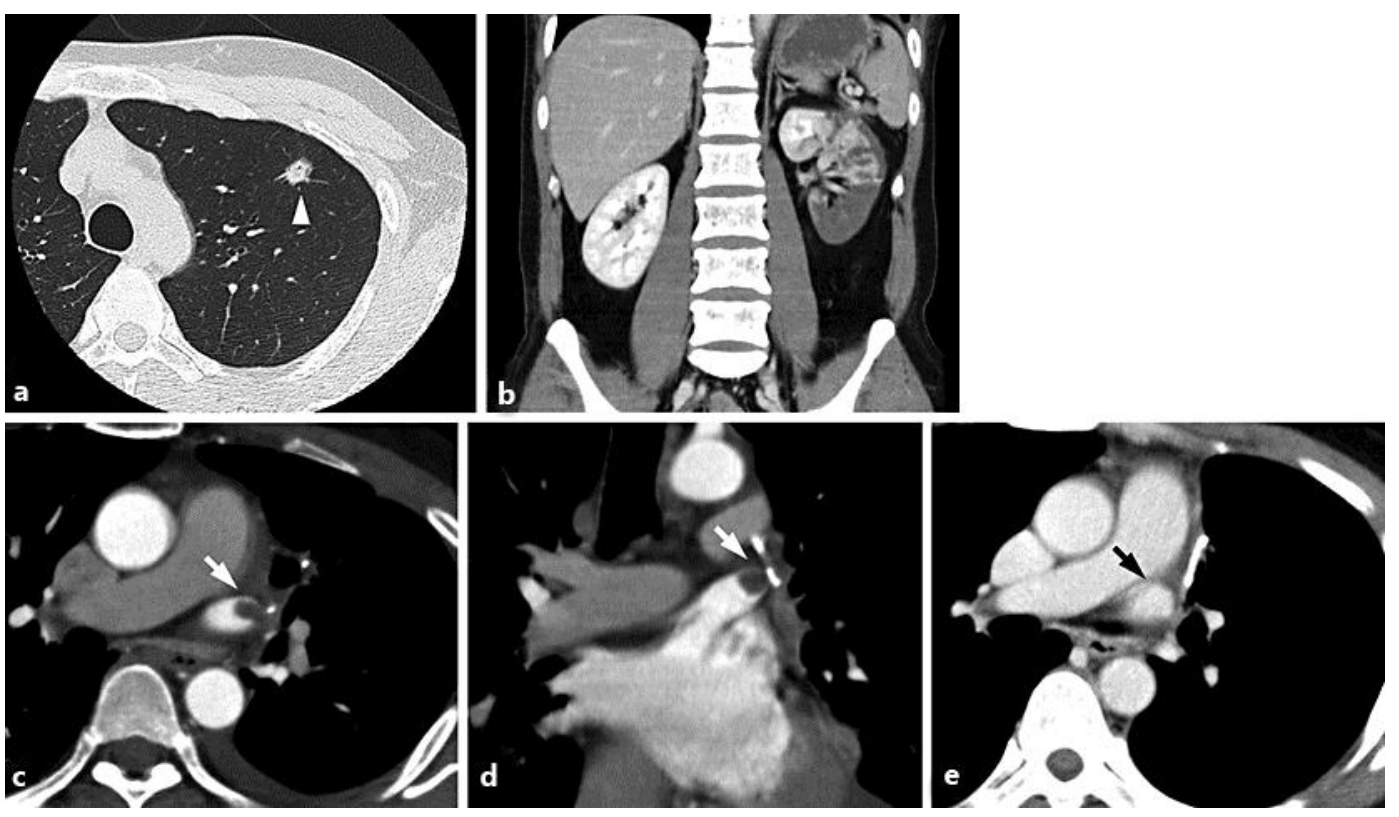

Fig. 1. a Preoperative CT of the chest reveals a nodular shadow in the upper lobe of the left lung (arrowhead). b Enhanced CT reveals a large wedge-shaped defect in the left kidney. c, $\mathbf{d}$ Enhanced CT after the diagnosis of renal infarction reveals a round defect in the stump of the left superior pulmonary vein (white arrow). e Enhanced CT 2 months after renal infarction reveals resolution of thrombosis (black arrow). 